\section{MUSĒUM \\ NAL H'ST \\ NATURELLE}

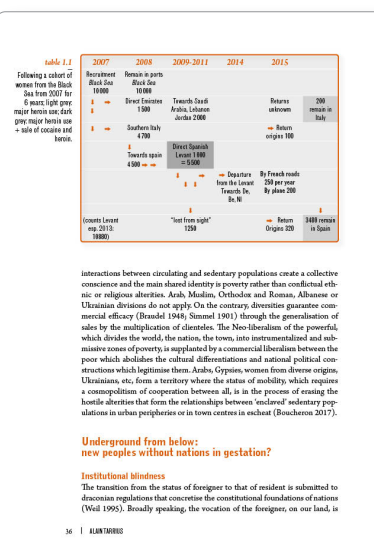

HUMAN
AND SOCIAL
SCIENCES
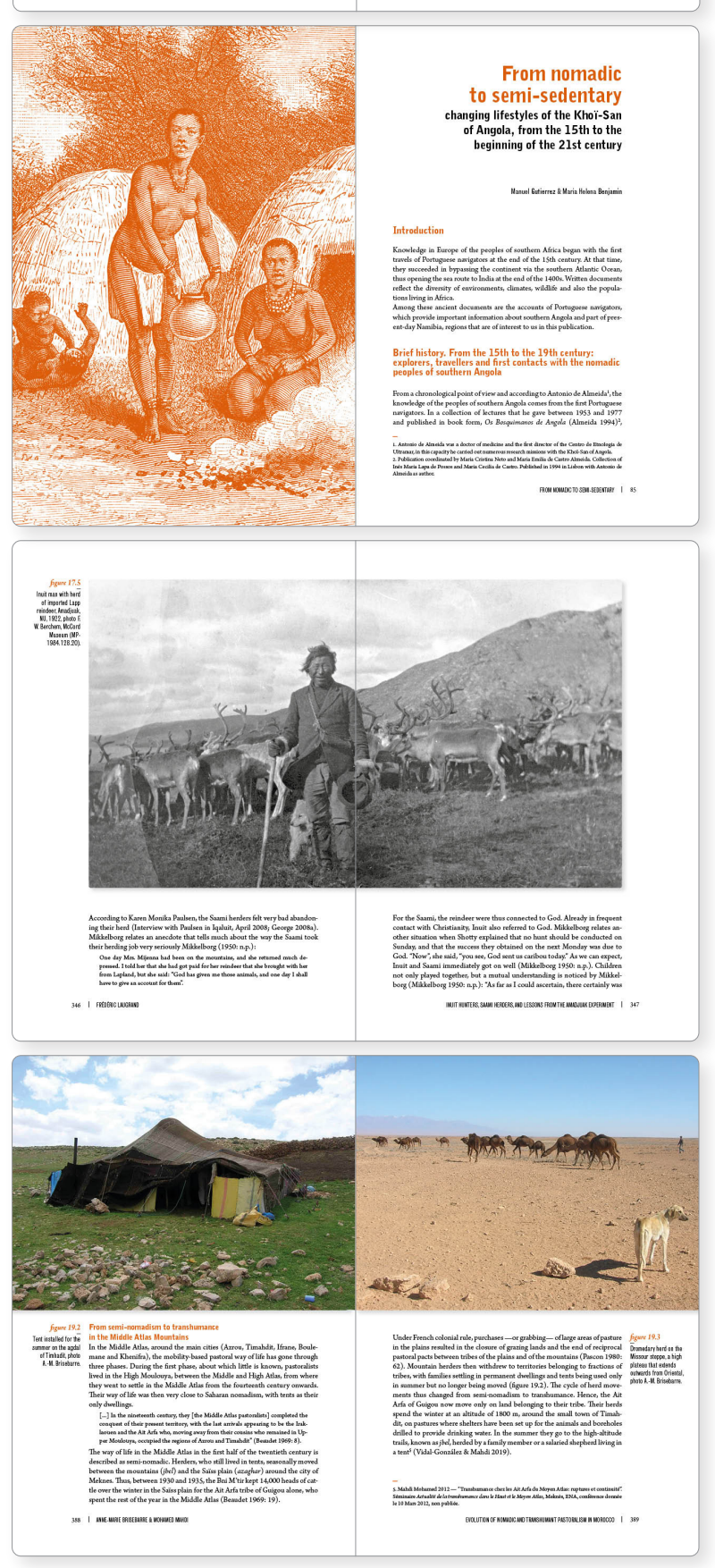

Socieres

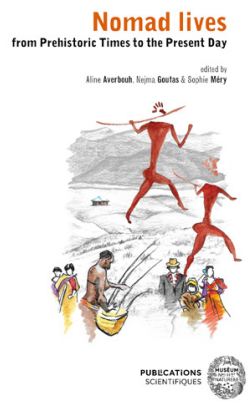

Series Natures en sociétés

tome $\mathbf{4}$

$165 \times 240 \mathrm{~mm}$ paperback

text in English

671 pages, 215 figures

ISBN 978-2-85653-966-8

$45 €$ TTC | 42,65 € VAT Excluded

Published on 25th November 2021

\title{
Nomad lives \\ from Prehistoric Times to the Present Day
}

edited by Aline Averbouh, Nejma Goutas \& Sophie Méry

\section{THE BOOK}

This book illustrates fragments of the lives of past and present "nomadic" peoples, from Africa, Asia, North and South America and Europe, from different angles (habitats, material production, economic and territorial organisation, social organisation, rites and beliefs, art). This way of life prevailed for millions of years before another sedentary way of life gradually replaced it from 9,000 years ago onwards. However, nomads did not disappear. Today they are a minority and are often marginalised, but they are still an integral part of our humanity.

This is the point of view we have adopted in Nomad Lives and we invite our readers to discover women, men and children from all sorts of geographical, climatic, sociological and even chronological horizons, all united by their nomadic lifestyle. This book contains nearly thirty contributions by archaeologists, ethnologists/anthropologists, sociologists, geographers, economists and historians.

However, present-day nomads are not in any way considered as avatars of past nomads, any more than the nomads of today (or yesterday) would be representative of one and the same social and economic organisation, of one and the same relationship to the world. On the contrary, the diversity of the contributions gathered here underlines the plural character of this way of life. Being nomadic, living as a nomad, cannot be defined in a univocal way and throughout the pages a question emerges, simple in appearance but excessively complex in the reality of the peoples themselves and of researchers in human sciences: "What is it to be nomadic?" it is around this question that the book closes from the combined perspective of an archaeologist, an ethnologist and a sociologist.

\section{THE EDITORS}

Aline Averbouh is an archaeologist, Senior Research fellow at the French National Centre for Scientific Research, specialist in prehistoric nomadic groups of the late Upper Palaeolithic.

Nejma Goutas is an archaeologist, Research fellow at the French National Centre for Scientific Research, specialist in prehistoric nomadic groups of the Early Upper Palaeolithic (Gravettian) in Europe. Sophie Méry is an archaeologist, Research Director at the French National Centre for Scientific Research, she is a specialist in Neolithic and Bronze Age societies in Arabia.

Orders and information Muséum national d'Histoire naturelle Publications scientifiques $\cdot \mathrm{CP} 41 \cdot 57$ rue Cuvier • 75231 Paris cedex 05 tél. [33] (0)। 407948 05 • fax [33] (0)। 40793840 • diff.pub@mnhn.fr

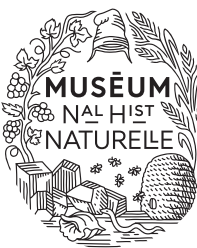

